\title{
Convenience foods from foxtail millet and garden cress seed
}

\author{
S.M. Rodge and H.P. Bobade
}

Received : 10.04.2018; Accepted : 13.04.2018

See end of the Paper for authors' affiliation

Correspondence to :

\section{S.M. Rodge}

Department of Agricultural Engineering, Maharashtra Institute of Technology, Aurangabad (M.S.) India Email : shradharodge1994@ gmail.com abstract : India is a major millet producing with $38.6 \%$ of total millet producing of world and one of the countries of major utilization. Millets are comparative with major cereals like wheat and rice with respect to nutritional value and parts of diet of poor due to less cost. Convenience foods impact convenience to the consumers with, no requirement of major processing or cooking before consumption. Instant upma mixes are the most convenient stable foods which required reconstitution in boiling water for 2 to $10 \mathrm{~min}$. Rapid urbanization, industrialisation and changes in eating habits of people lead to development of such foods. Millets contains vitamins, minerals, sulphur containing amino acids and some phytochemicals and therefore described as nutritious millets, which release sugars slowly and thus have a low glycaemic index and can do ideal foods for diabetes and also free from gluten makes than ideal for celiac peoples. Market available ready to cook mixes are deficient in essential macro and micro nutrients. Foxtail millet (Setaria italica) has good nutritional profile as compared to rice and wheat in item of nutrients. Garden cress (Lepidium sativum) due to their high potential in health promotion and disease prevention can be incorporated in instant upma mix at low level. Popping of foxtail millet and garden cress seeds imparts acceptable taste and desirable aroma. It also reduces the level of antinutrients such as tannin, phytic acid and oxalic acids and improved the digestibility of starch and protein in vitro.

- Key words : Convenience foods, Foxtail millet, Garden cress, Popping, Digestibility

- How to cite this paper : Rodge, S.M. and Bobade, H.P. (2018). Convenience foods from foxtail millet and garden cress seed. Internat. J. Agric. Engg., 11(Sp. Issue) : 164-168, DOI: 10.15740/HAS/ IJAE/11.Sp. Issue/164-168. 